\title{
Determination of physico-chemical properties of pomegranate (punica granatum L.) fruits of Dar es Salaam Tanzania
}

\author{
Lugwisha Esther Hellen", *, Fabian Christina ${ }^{2}$, Othman Chande Othman ${ }^{1}$ \\ ${ }^{1}$ University of Dar es Salaam, Chemistry Department, P. O. Box 35061, Dar es Salaam, Tanzania \\ ${ }^{2}$ Mkwawa University College of Education, Chemistry Department, P. O. Box Private Bag, Iringa, Tanzania
}

\section{Email address:}

elugwisha@gmail.com (L. E. Hellen),tina84f@yahoo.com (F. Christina),o_chande@yahoo.co.uk (O. C. Othman)

\section{To cite this article:}

Lugwisha Esther Hellen, Fabian Christina, Othman Chande Othman. Determination of Physico-Chemical Properties of Pomegranate (punica granatum L.) Fruits of Dar es Salaam Tanzania. Journal of Food and Nutrition Sciences. Vol. 2, No. 6, 2014, pp. 277-284.

doi: $10.11648 /$ j.jfns.20140206.16

\begin{abstract}
The physicochemical composition of pomegranate (Punica granatum L.) fruits from Kimara, Dar es Salaam during open air storage ripening process were determined. The ash, titratable acidity, crude fat, crude fiber, moisture and sugars content were determined by proximate analysis. Ascorbic acid contents were determined using the 2,6-dichlorophenol-indophenol dye method while mineral elements and heavy metals were determined by Flame Atomic Absorption Spectrophotometry (FAAS). The fruits were always harvested at the mature stage and allowed to ripen during open air storage. The determinations were done immediately after arrival at the laboratory and thereafter at intervals of two days from the day of harvest to the $8^{\text {th }}$ day. The results showed that fresh pomegranate fruits had high moisture content range of $(89.6 \%-77.5 \%)$, low titratable acidity $(<0.86 \%$ ca), low crude fat $(0.30 \mathrm{~g} / 100 \mathrm{~g}$-fw $)$, low ash content $(0.35 \mathrm{~g} / 100 \mathrm{~g}-\mathrm{fw})$, moderate crude fibre content $(4.20 \mathrm{~g} / 100 \mathrm{~g}$-fw), high ascorbic acid content (53.7 - $20.4 \mathrm{mg} / 100 \mathrm{~g}-\mathrm{fw})$, high total sugars content $(48.9 \%-29.1 \%)$, moderate reducing sugar content (42.0\% $25.5 \%)$ and sucrose content $(5.7 \%-2.0 \%)$. Of the mineral elements $(\mathrm{K}, \mathrm{Ca}$ and $\mathrm{Na})$ determined, the highest content was of $\mathrm{Ca}$ $(1086 \mathrm{mg} / 100 \mathrm{~g}$-fw.). Heavy metals (Fe, $\mathrm{Zn}, \mathrm{Cu}, \mathrm{Pb}$ and $\mathrm{Cd}$ ) content was very low in the pomegranate fruits, ranging between $<0.0015 \mathrm{mg} / 100 \mathrm{~g}$-fw for $\mathrm{Cd}$ and $0.84 \mathrm{mg} / 100 \mathrm{~g}$-fw for Fe. Except for sucrose which was increasing during storage ripening, the moisture content, acidity content, ascorbic acid content, total sugar content and reducing sugar content were all decreasing as the fruit was ripening while in storage. There were no significant changes during storage ripening for levels of crude fat, ash, minerals and heavy metals. The results of this study suggest that these fruits could highly contribute in the improvement of the nutrition of consumers.
\end{abstract}

Keywords: Pomegranate, Punica Granatum L., Physico-Chemical, Proximate Analysis, Fruits, Storage Ripening, Macronutrients, Atomic Absorption Spectrosccopy, Tanzania

\section{Introduction}

Knowledge on the nutrient composition of locally available foods has become of greater importance because of the need to supply food according to their nutritive value to the increasing population of the world. Dietary supplementation using different fruits, vegetables and also herbs is now a major route towards curative as well as preventive approach to combating diseases and poor health. For Tanzania, as it is for other developing countries, there exists very little information on the nutritive value of its natural foods especially fruits so that these may be used for such purposes. Pomegranate (Punica granatum L.) fruits are important fruits in Tanzania as they are a good source of vitamins, dietary fiber and minerals and provide flavor, aroma and texture to the pleasures of eating. The pomegranate fruits are normally eaten fresh or as fresh pomegranate juice. There is growing interest in this fruit because it is considered to be a functional product of great benefit in the human diet as it contains several groups of substances that have anti-cancer [1] and antioxidant properties [2-3] that are useful in disease risk reduction.

Since fresh fruits have living respiring tissues, 
physiological processes between harvesting and consumption can result in the loss of quality of fruits. Postharvest physiology studies seek to understand the basic physiological changes that occur in a detached fruit during ripening and storage [4]. Thus in recognition of the importance of fruits as valuable food resources, more research is required in order to understand the physical and chemical composition, and physiological changes that occur during storage and ripening of locally available fruits in the community such as pomegranate, so that quality, physicochemical characteristics and storage ripening changes of the properties of fruits should be established. As such this study was undertaken.

Several research studies have been undertaken on the physico-chemical composition of Tanzanian fruits and a few documented studies include those on mangoes [3], pineapples [5], papaya [6] and oranges [7]. So far little attention has been paid to less popular fruits such as pomegranates. Heavy metal pollution has provoked considerable research in the analysis of food and food products [8]. Heavy metals have been reported to have positive and negative roles in human life [9 11]. Some metals like cadmium, lead and mercury are major contaminants of food supply and may be considered the most dangerous elements to our environment while others like iron, zinc and copper are essential for biochemical reactions in the body [12].

This study therefore reports on the proximate composition (moisture, acidity, sugars, ash, crude fibers and crude fat content), ascorbic acid content, mineral elements and heavy metals content in pomegranate fruits of Kimara, Dar es Salaam, Tanzania.

\section{Material and Methods}

\subsection{Reagents}

The following analytical grade reagents were used in this study: hydrochloric acid (assay $37 \mathrm{w} / \mathrm{v}$, specific gravity 1.2), sulphuric acid (assay 95-98 w/v, specific gravity 1.840) and standard ascorbic acid (assay 99.7\%) as supplied by Aldrich Chemical Company Ltd, England. Copper sulphate (99\%) was obtained from Lab Tech chemicals Ltd and sodium hydroxide pellets (assay 97\%) were obtained from Techno Pharmchem India. 2,6-dichlorophenol-indophenol A.C.S. reagent and phenolphthalein indicator used were supplied by LOBAL Chemie Company. Potassium and sodium tartrate (assay 99\%) and citric acid (monohydrate) assay $99.8 \%$ were supplied by Riedel-de Haen AG and ethanol (assay 95\% pure) was supplied by CARLO ERBA Reagents of Italy. Deionized distilled water was used for all needed dilutions.

The following analytical grade reagents were also used in the reaction processes within this study: acetic acid (glacial assay 99.5\%), nitric acid, perchloric acid, metaphosphoric acid (assay 88\% w/w) and methylene blue indicator as obtained from B.D.H Ltd, England, Lead acetate (assay < 99\%), potassium oxalate (assay 99.5\%) and phenolphthalein indicator ( $\mathrm{pH}$ range 8.3-10) were obtained from May \& Baker Ltd. Dagenham, England. Petroleum-ether (bp 60-80 ${ }^{\circ} \mathrm{C}$ ) was obtained from the Central Drug House Ltd. of India.

\subsection{Instruments and Equipment}

An electronic balance Mettler Toledo model B 303-S, a Genlab oven supplied by Wideness Cheshire Ltd. having a temperature range of 0 to $250{ }^{\circ} \mathrm{C}$ and a muffle furnace, Gallenkamp Rapid Model, from Gallenkamp Ltd, having a heating temperature range up to $1000{ }^{\circ} \mathrm{C}$ were used. The Gallenkamp Centrifuge model 200 with frequency of $50 \mathrm{~Hz}$ from Gallenkamp Ltd, Osterizer blendor model 867-66A, an IKAMAG-RET type hot plate, a HANNA waterproof pH-meter, a heating mantle of one litre, a soxhlet apparatus and the Flame Atomic Absorption Spectrophotometer, model iCE 3000 v1.3 instrument were also used.

\subsection{Fruit sample Collection}

Samples of pomegranate fruits were collected from Kimara farms in Dar es Salaam. Fully matured fruits were picked directly from trees and were transported to the Chemistry Department laboratory, University of Dar es Salaam, for room temperature storage ripening experiments and for further preparations and analysis.

\subsection{Analysis}

The following determinations were done immediately after arrival at the laboratory and thereafter at intervals of two days from the day of harvest to the $8^{\text {th }}$ day.

\subsection{Moisture Content}

A clean porcelain crucible was dried in an oven at $110^{\circ} \mathrm{C}$ for $1 \mathrm{~h}$, cooled in a desiccator and weighed. About $20 \mathrm{~g}$ of fresh fruit sample were spread in the crucible, weighed as quickly as possible to determine its exact weight and dried in a hot air oven at $70^{\circ} \mathrm{C}$ for $16 \mathrm{~h}$. This was then followed by cooling in a desiccator and weighing until a constant weight was attained. The moisture determination for each sample was done in triplicate and the average value recorded as percent moisture [13].

\subsection{Titratable Acidity}

$10 \mathrm{~g}$ of the minced fresh fruit sample were mixed with 200 $\mathrm{mL}$ of distilled water and boiled for $1 \mathrm{~h}$. The mixture was cooled, filtered and the filtrate transferred to a $250 \mathrm{~mL}$ volumetric flask and made up to the mark. $10 \mathrm{~mL}$ of the filtrate was titrated with $0.1 \mathrm{M} \mathrm{NaOH}$ using $1 \%$ phenolphthalein solution as indicator. The results were expressed as \% citric acid [14]. All determinations was done in triplicate and the average values were recorded.

\subsection{Ash Content}

$5.0 \mathrm{~g}$ of the sample were placed in a dry porcelain crucible, dried in a hot air oven for $16 \mathrm{~h}$. The dried sample was placed in a muffle furnace and ashed at temperature of around $525^{\circ} \mathrm{C}$ for $6 \mathrm{~h}$. The ash was then cooled in a desiccator and weighed. The weight was recorded as g per $100 \mathrm{~g}$ fresh weight ( $\mathrm{g}-\mathrm{fw}$ ) 
[14]. The determination was done in triplicate and the average value was recorded.

\subsection{Crude Fat}

The weighed dried fruit sample was put into a thimble and covered with fat free cotton. The thimble was then put into the soxhlet apparatus. The flask was filled with $150 \mathrm{~mL}$ petroleum ether and extraction was done for $16 \mathrm{~h}$. At the end the sample was dried at $100{ }^{\circ} \mathrm{C}$ in an oven for $1 \mathrm{~h}$, then cooled to room temperature and re-weighed. The difference in the weights gave the fat-soluble material present in the sample. Determinations were done in triplicate and the average value was recorded [14].

\subsection{Crude Fibers}

$2 \mathrm{~g}$ of residue remaining from the crude fat determination was poured in a digestion flask followed by $200 \mathrm{~mL}$ of boiling $0.1275 \mathrm{M}$ sulphuric acid. The mixture in the flask was immediately connected to a condenser and the mixture heated for $30 \mathrm{~min}$. The material was then filtered and washed thoroughly with boiling distilled water until the washings were no longer acidic. A $0.313 \mathrm{M} \mathrm{NaOH}$ solution was boiled under reflux and the washed material added to it. The content in the flask were connected to the reflux condenser and boiled for $30 \mathrm{~min}$. The material was then filtered in a filtering cloth in a fluted funnel and washed thoroughly with distilled water followed by $15 \mathrm{~mL}$ of alcohol. The contents were finally dried at $110{ }^{\circ} \mathrm{C}$ to a constant weight, cooled in a dessicator and weighed. The material was then ashed. The loss in weight represents the crude fiber amount of the fruit. The procedure of Mbogo et al. [8] and Ranganna [14] was followed.

\subsection{Sugars}

The reducing sugar in the fruits were determined by titration method where clarified fruit solution was titrated against mixed Fehling's solution using methylene blue as an indicator. Total sugar was also determined by titration but before titration there was an addition of citric acid and the solution was boiled in order to complete the inversion of sucrose. Total sugars, reducing sugars and sucrose content in the pomegranate fruits were determined following the procedures of method 932.12 of AOAC [15].

\subsection{Ascorbic Acid}

$5 \mathrm{~g}$ of fresh fruit sample were blended with $25 \mathrm{~mL}$ of $5 \%$ metaphosphoric acid solution. The mixture was filtered through a Whatman No. 42 filter paper. The residue was then washed with $5 \%$ metaphosphoric acid until the total volume of the collected filtrate was $50 \mathrm{~mL}$. The filtrate was then centrifuged at 2000 r.p.m for $20 \mathrm{~min} .10 \mathrm{~mL}$ of the clear filtrate was pipetted in to a conical flask and titrated against a $0.025 \%$ 2,6-dichlorophenol-indophenol reagent. The titration was done in triplicate and the average titre value was recorded. The $0.025 \%$ 2,6- dichlorophenol- indophenol reagent was standardized using standard ascorbic acid solution as described by AOAC [15].

\subsection{Minerals and Heavy Metals}

$1 \mathrm{~g}$ of a well dried and powdered fruit sample was placed in a digestion bottle followed by addition of $8 \mathrm{~mL}$ conc. nitric acid and $2 \mathrm{~mL}$ perchloric acid. The solution was then heated for about $4 \mathrm{~h}$ with slow addition of drops of perchloric acid until a clear solution was obtained. The solution was then transferred to a $50 \mathrm{~mL}$ volumetric flask and made up to the mark by distilled water. Appropriate dilution was done for elements present at high concentrations.

\subsection{Atomic Absorption Spectrophotometry (AAS)}

All determinations of metals were performed with the iCE 3000 v1.3 AAS instrument equipped with Zeeman background correction. Hollow cathode lamps of the different metals were used as radiation sources for the instrument. The instruction manual of the instrument was used as guide for all measurements. Calibration standards were first aspirated into the AAS to calibrate the instrument and check its linearity response. After all necessary set up, standardization and calibration procedures had been completed then the above treated fruit juice sample solutions were aspirated into the AAS instrument for precise measurement of metal concentration. All determinations, in triplicate, were performed at the laboratory of the Chemistry Department, University of Dar es Salaam.

\section{Results and Discussion}

The experimental results on proximate compositions (moisture, acidity, reducing sugars, total sugars, sucrose) and ascorbic acid content of pomegranate (Punica granatum L.) fruit are reported in Table 1. The results on determinations of ash, crude fat and crude fibre content are reported in Table 3. The results of determinations of mineral elements and heavy metals are reported in Table 4. All results are average results of triplicate determinations.

\subsection{Moisture Content}

Moisture content is the quantity of water contained in a material, such as a fruit. Different studies have shown the variations in moisture contents in different fruits during ripening and storage periods [16, 17, 18, 19]. According to Mitchel et al. [20] increase in moisture content reduces the proximate principles such as fat, protein and carbohydrate thereby decreasing the energy value. During storage ripening of the pomegranate fruits a decrease in moisture content from $89.6 \%$ when harvested to $77.5 \%$ on $8^{\text {th }}$ day of storage was observed (Table 1). This decrease in moisture has also been reported by Al-Maiman and Ahmad [21] for Saudi Arabian pomegranate fruits and Othman [5] for Tanzanian pineapple fruits. The decrease is due to the evaporation of moisture from the surface of the fruit during the storage ripening period [16]. Nazarudeen [17] reported a decrease in value from $86 \%$ to $78 \%$ moisture content of pomegranate fruits and Ajay et al. [22] reported a value of $78 \%$ moisture content for wild Indian pomegranate fruits. These reports compare well to the values obtained in this study. 
Table 1. Proximate composition (moisture, acidity, reducing sugars, total sugars, sucrose) and ascorbic acid content of pomegranate (punica granatum L.) fruits of Dar es Salaam

\begin{tabular}{lllll}
\hline Storage-ripening days Parameter $(\mathbf{n}=\mathbf{3})$ & $\mathbf{0}$ & $\mathbf{2}$ & $\mathbf{4}$ & $\mathbf{6}$ \\
\hline Moisture (\%) & $89.6 \pm 3.3$ & $87.3 \pm 2.1$ & $86.2 \pm 4.2$ & $84.0 \pm 1.1$ \\
Titratable acidity (\%) & $0.86 \pm 0.03$ & $0.77 \pm 0.05$ & $0.51 \pm 0.04$ & $0.43 \pm 0.02$ \\
Reducing sugars (\%) & $42.0 \pm 3.5$ & $38.9 \pm 2.4$ & $35.1 \pm 4.4$ & $29.4 \pm 3.2$ \\
Total sugars (\%) & $48.9 \pm 1.5$ & $46.1 \pm 2.5$ & $42.7 \pm 2.6$ & $3.3 \pm \pm 0.06$ \\
Sucrose (\%) & $2.0 \pm 0.8$ & $2.3 \pm 0.4$ & $5.4 \pm 2.6$ & $25.5 \pm 1.6$ \\
Ascorbic acid (mg/100 g-fw) & $53.7 \pm 1.4$ & $50.1 \pm 2.1$ & $32.2 \pm 2.6$ & $29.1 \pm 3.6$ \\
\hline
\end{tabular}

\subsection{Titratable Acidity}

Acidity in fruits is an important factor in determining maturity. Many fruits have high acidity early in the season, making them unacceptable to consumers even though they meet minimum sugar standards. So acidity plays a significant role in taste, color, and microbial stability of the fruit juice.

Decrease in titratable acidity (a measure of the amount of acid present in a solution) was observed during storage ripening of pomegranate fruits. This reduction of acidity might be due to utilization of constituent acids in the respiratory processes [28]. This behavior has also been reported by Al-Maiman and Ahmad [21] for Saudi Arabian pomegranate fruits. The observed titratable acidity values for pomegranate fruit during storage-ripening are presented in Table 1. At the time of picking, the pomegranate fruits had $0.86 \%$ citric acid while by the $8^{\text {th }}$ day of storage the level had changed to $0.38 \%$ ca. These values are within the range of $0.35 \%$ to $3.36 \%$ ca for Iranian pomegranate fruits reported by Zarei et al. [26]. However these values are lower than the values of $0.95-1.5 \%$ citric acid in pineapple fruits of Tanzania reported by Othman [5]. The values of titratable acidity in this study make these fruits acceptable to consumers.

\subsection{Sugars}

During storage ripening of a pomegranate fruits, there was a decrease of total sugar and reducing sugar with an increase of sucrose. Pomegranate had an initial total sugar content of $48.9 \%$ at harvest and $29.1 \%$ by the $8^{\text {th }}$ day of storage (Table 1 ). This value is high compared to a value of $16.6 \%$ for Indian pomegranate fruits reported by Ajay et al. [22] and a value of $14.1 \%$ for Saudi Arabian pomegranate fruits reported by Al-Maiman and Ahmad [21]. Both added sugar and naturally occurring sugar have the same amount of calories. When sugars are consumed in large amounts they can easily lead to weight gain and other sugar-related health problems. Fruits have high amounts of vitamins and minerals, so even though pomegranate fruits have high amount of sugar they can still be consumed due to the other advantages. The reducing sugar content of pomegranate fruits at harvest was $42.0 \%$ and by the $8^{\text {th }}$ day of storage this had reduced to $25.5 \%$. These values are higher than the values of $13.9 \%$ to $29.8 \%$ for Iranian pomegranate reported by Vahid et al. [29]. The sucrose content of the fruit at harvest was $1.9 \%$ and by the $8^{\text {th }}$ day of storage this had increased to $7 \%$. The increase in sucrose might be due to enzymatic break down of polysaccharides into sugars [30]. This increase in sucrose is very important as it improves the sweetness of the fruit, a very important factor for the fruit consumers.

\subsection{Ascorbic Acid}

Ascorbic acid is a water soluble, crystalline compound with strong reducing property [23]. Ascorbic acid contains many of the same health benefits as naturally occurring vitamin $\mathrm{C}$. The richest sources of ascorbic acid (vitamin C) are fruits and vegetables.

Ascorbic acid content of the studied pomegranate fruits decreased during storage ripening (Table 1). A similar observation has been reported by Al-Maiman and Ahmad [21] for Saudi Arabian pomegranate fruits. The highest value of ascorbic acid in the pomegranate fruits was $53.7 \mathrm{mg} / 100 \mathrm{~g}-\mathrm{fw}$ at day 0 and decreased to $20.4 \mathrm{mg} / 100 \mathrm{~g}$-fw at day 8 (Table 1). The high values of ascorbic acid in pomegranate signify the potential use of the fruit as a good antioxidant and can help ward off a variety of health problems such as lowering the risk of heart disease, blood pressure, and carcinogens. It is also generally used for protein metabolism and collagen synthesis. However, such ascorbic acid levels for Tanzanian pomegranate are comparable to the value of $51.8 \mathrm{mg} / 100 \mathrm{~g}-\mathrm{fw}$ for Hawaii papaya fruits reported by Wall [24] but is lower than the value of $84.5 \mathrm{mg} / 100 \mathrm{~g}$-fw for Eastern Tanzanian papaya fruits reported by Othman [6]. The recommended daily intake (RDI) of ascorbic acid is about $30 \mathrm{mg} /$ day for adults and $17 \mathrm{mg} /$ day for children. Therefore, these fruits could be considered as good sources of ascorbic acid for purposes of human nutrition.

A comparative look at the results of physicochemical studies of pomegranates reported by other researchers is presented in Table 2. The results show a wide variation of the values for the different parameters as the fruits are grown in different soils, climates and geographical locations. The percent moisture content is similar in the fruits, the percent acidity varies from 0.32 (India) [25] to 1.35 (Iran) [26], the percent total sugars content varies from 7.8 (Iran) [26] to 48.9 (Tanzania) [this study], the reducing sugars from 4.9 (Iran) [26] to 42 (Tanzania) [this study], sucrose varies from 1.4 (Tunisia) [25] to 2.0 (Tanzania) [this study], and ascorbic acid content varies from 9.5 (India) [27] to $67 \mathrm{mg} / 100 \mathrm{~g}$-fw (South Africa) [3].

\subsection{Ash}

The ash content is a measure of the total amount of minerals such as sodium, potassium and iron present within food. The main purpose of ash determination is to assess the quality of 
the food materials. Although such minerals constitute only a small portion (ca. $4.0 \%$ ) of the body tissue, they are essential as structural components for carrying out many vital processes in the body (17). A high total ash content for a food material signifies the presence of adulterants [21]. The pomegranate fruits from Kimara, Dar es Salaam, had an average ash content of $0.35 \pm 0.09 \mathrm{~g} / 100 \mathrm{~g}$-fw (Table 3). This value compares well to the value of $0.33 \mathrm{~g} / 100 \mathrm{~g}$-fw for Saudi Arabian pomegranates [21] but is however lower than the value of the ash content found for Indian pomegranates [25]. This value is also less than the value of $0.68-0.78 \mathrm{~g} / 100 \mathrm{~g}$-fw for Tanzanian oranges as reported by Mbogo et al. [8]. Thus this study suggests that the Kimara pomegranate fruits have moderate deposits of mineral elements.

Table 2. Comparative data on proximate composition and ascorbic acid content of pomegranate (punica granatum L.) fruits

\begin{tabular}{lll}
\hline Attribute & This study & Literature \\
\hline Moisture (\%) & 89.6 & $80.5[25]$ \\
& & $1.35[26], 0.405[26], 0.35[27]$, \\
Titratable acidity (\%) & 0.86 & $0.32[25]$ \\
Reducing sugars (\%) & 42.0 & $4.9[26], 12.3[25]$ \\
Total sugars (\%) & 48.9 & $7.8[26], 17.8[24], 13.5[25]$ \\
Sucrose (\%) & 2.0 & $1.7[25], 1.4[41]$ \\
Ascorbic acid & 53.7 & $67.0[3], 11.9[26], 25.8[24], 9.5$ \\
(mg/100 g-fw) & & {$[27]$} \\
\hline
\end{tabular}

Table 3. Ash, crude fat and crude fiber content in pomegranate (punica granatum L.) fruit of Dar es Salaam, Tanzania

\begin{tabular}{lll}
\hline \multirow{2}{*}{ Attribute } & \multicolumn{2}{l}{ Concentration (mean \pm SD in $\mathbf{g} / \mathbf{1 0 0}$ g-fw) } \\
\cline { 2 - 3 } & This study $\mathbf{~}=\mathbf{3}$ & Literature \\
\hline Ash & $0.35 \pm 0.09$ & $0.33[21], 0.80[25]$ \\
Crude fat & $0.30 \pm 0.12$ & $0.2[17], 0.25[25]$ \\
Crude fiber & $4.2 \pm 0.9$ & $2.1[49], 0.82[25]$ \\
\hline
\end{tabular}

fw-fresh weight

\subsection{Crude Fat}

Crude fat represents the true fat and other materials such as phospholipids, sterols, essential oils and fat soluble pigments in the fruit. Generally fruits have low levels of fat content and this suggests that they are not good sources of energy. The average crude fat in pomegranate fruits obtained in this study was $0.30 \pm 0.12 \mathrm{~g} / 100 \mathrm{~g}$-fw (Table 3), a bit higher than the $0.25 \mathrm{~g} / 100 \mathrm{~g}$ values recommended by EU/WHO for fruit groups. However, the value reported in this study is higher than the value of $0.2 \mathrm{~g} / 100 \mathrm{~g}$-fw for Indian pomegranate fruits as reported by Nazarudeen [17] and $0.22 \mathrm{~g} / 100 \mathrm{~g}-\mathrm{fw}$ for Tanzanian mangoes reported by Othman and Mbogo [5]. The low level of fat in the fruits means that these fruits are not good source of energy [24] and are recommended for loss or maintaining of weight, supply of nutrients and lowering of blood pressure $[31 ; 32]$.

\subsection{Crude Fiber}

Crude fiber includes only those components that remain after chemical extraction of plant materials with solvents followed by digestion with dilute acid and alkali and it comprises only a small fraction of dietary fibers $10 \%-50 \%$ [33]

In pomegranate fruits the crude fiber content observed in this study was $4.20 \pm 0.94 \mathrm{~g} / 100 \mathrm{~g}$-fw (Table 3 ) which is relatively higher than the EU/WHO recommended limit of 2.5 $\mathrm{g} / 100 \mathrm{~g}$ for fruits. The value in this study is also higher than the values of 2.1 and $0.82 \mathrm{~g} / 100 \mathrm{~g}$-fw for Indian pomegranate fruits reported by Punna and Paruchuri [34] and Priyanka et al. [25] respectively. Fiber is essential to the human body as it helps to maintain the health of the gastrointestinal tract and in weight regulation [34 - 37] but if consumed in excess it may bind trace elements, leading to deficiency of iron and zinc in the body [38]. The observed level of crude fiber in Tanzanian pomegranates is moderate and thus good for body maintenance.

\subsection{Macroelements}

Mineral elements are inorganic elements which are regarded as absolutely essential to all of life's processes. Mineral requirement of the body has placed minerals in two groups; the macro minerals (macroelements or macronutrients) which are required in large quantities; they include calcium, magnesium, potassium, sodium, chlorine, phosphorus and sulphur and the micro minerals (microelements or micronutrients or trace elements), those elements which are required in small quantities; consisting of cobalt, copper, iodine, iron, manganese, selenium, zinc, chromium, fluorine and molybdenum [39].

The contents of selected macroelements in the pomegranate fruits studied are summarized in Table 4. Calcium was the predominant mineral element present in the fruit. The average calcium level in pomegranate fruits was $1086 \pm 49 \mathrm{mg} / 100$ g-fw, a level that is much higher than the values of 43 and 5 $\mathrm{mg} / 100 \mathrm{~g}$-fw reported for Saudi Arabian [21] and Indian [25] pomegranate fruits respectively. This high value of calcium in the Tanzanian pomegranate fruits suggests that these fruits can be used to contribute significantly to the daily dietary calcium body requirement of $2500 \mathrm{mg} /$ day [40]. Thus the pomegranate fruits may be useful for the strengthening of bones in the body.

The average amount of potassium in pomegranate fruits was $538 \pm 96 \mathrm{mg} / 100 \mathrm{~g}-\mathrm{fw}$ (Table 4). This value is high when compared to the values of $236 \mathrm{mg} / 100 \mathrm{~g}$-fw for Indian pomegranate fruits [22], $253 \mathrm{mg} / 100 \mathrm{~g}-\mathrm{fw}$ for Saudi Arabia pomegranate fruits and $132 \mathrm{mg} / 100 \mathrm{~g}$-fw also for pomegranates from India [25]. The amount of potassium in the Tanzanian pomegranate fruits studied can be considered low since the level contributes very little to the recommended daily allowance (RDA) for potassium which is $2000 \mathrm{mg}$ /day for an adult [40].

The average sodium content in the pomegranate fruits was $675 \mathrm{mg} / 100 \mathrm{~g}$-fw (Table 4), a value higher than the values of 76 and $6.7 \mathrm{mg} / 100 \mathrm{~g}-\mathrm{fw}$ for Saudi Arabian [21] and Tunisian [26] pomegranate fruits respectively. The pomegranate fruits can contribute significantly to the daily amount of sodium needed by the body since the RDA value for sodium for adults is $500 \mathrm{mg} /$ day [40] and are therefore recommended for this. 
Table 4. Macroelements and heavy metals content in pomegranate (Punica granatum L.) fruits of Kimara, Dar es Salaam.

\begin{tabular}{lll}
\hline \multirow{2}{*}{ Minerals } & \multicolumn{2}{l}{ Concentration (mean \pm SD in $\mathbf{~ m g} / \mathbf{1 0 0}$ g-fw) } \\
\cline { 2 - 3 } & This study $\mathbf{~}=\mathbf{3}$ & Literature \\
\hline Macroelements & $1086 \pm 49$ & $43[21], 5[25]$ \\
Calcium & & $76[21] ; 6.7[41]$ \\
Sodium & $675 \pm 43$ & $236[17] ; 218[41], 132[25], 253$ \\
Potassium & $538 \pm 96$ & {$[21]$} \\
Heavy metals & & \\
Iron & $0.84 \pm 0.31$ & $2.19[21], 0.11[43], 1.3[25]$ \\
Zinc & $0.45 \pm 0.10$ & $0.25[21], 0.35[22], 0.8[25]$ \\
Copper & $0.29 \pm 0.08$ & $0.07[21], 0.15[17], 0.32[25]$ \\
Lead & $0.19 \pm 0.03$ & ND* [21] \\
Cadmium & ND* & \\
\hline
\end{tabular}

*ND: Not Detected i.e. $<0.0015 \mathrm{mg} / 100 \mathrm{~g}-\mathrm{fw}$

\subsection{Heavy Metal Content}

Heavy metal is a general collective term which applies to the group of metals and metalloids with specific gravity that is at least 4 - 5 times the specific gravity of water. The specific gravity of water is 1 at $4{ }^{\circ} \mathrm{C}\left(39^{\circ} \mathrm{F}\right)$ [41]. Repeated intake of these metals may cause very serious problem in human beings as well as in other animals. This is because, heavy metals are not biodegradable hence they accumulate in the body. The adverse effect will usually only be known years later. Example of heavy metal toxicity due to lead is the mental impairment in children and in adults it affects the nervous system and kidneys [42].

The heavy metal levels observed in the pomegranate fruits are summarized in Table 4. The iron content in pomegranate was $0.84 \pm 0.31 \mathrm{mg} / 100 \mathrm{~g}$-fw, a value less than the values of $2.19 \mathrm{mg} / 100 \mathrm{~g}-\mathrm{fw}$ reported for Saudi Arabia pomegranate fruits [21] and $1.3 \mathrm{mg} / 100 \mathrm{~g}$-fw reported for Indian pomegranate fruits [25] and higher than the value of 0.11 $\mathrm{mg} / 100 \mathrm{~g}$-fw reported for Botswana fruits by Amarteifio [43]. The contribution of iron by this fruit to the normal dietary requirement is poor as the range obtained in this study is very much less than the range of the RDA for iron which is $8.0-20$ $\mathrm{mg} /$ day [40].

The copper content in the pomegranate fruits was $0.29 \pm$ $0.08 \mathrm{mg} / 100 \mathrm{~g}$-fw. This value is higher than $0.07 \mathrm{mg} / 100 \mathrm{~g}-\mathrm{fw}$ reported for Saudi Arabian pomegranate fruits [21] and 0.15 $\mathrm{mg} / 100 \mathrm{~g}$-fw reported for Indian pomegranate fruits [18] but less than the value of $0.32 \mathrm{mg} / 100 \mathrm{~g}$-fw reported for Indian fruits reported by Priyanka et al. [25]. The level of copper obtained in this study compares very well to the level of copper reported for mangoes by Othman and Mbogo [5] i.e. $0.16-0.21 \mathrm{mg} / 100 \mathrm{~g}$-fw. When these levels of copper are compared to the copper RDA level in foods of $1.2-3.2$ $\mathrm{mg} / 100 \mathrm{~g}$-fw, these fruits can be considered as poor contibuters to the RDA.

The level of zinc in pomegranate fruits was $0.45 \pm 0.10$ $\mathrm{mg} / 100 \mathrm{~g}$-fw which was higher than the value of $0.25 \mathrm{mg} / 100$ g-fw reported for Saudi Arabian pomegranate fruits [21] and $0.35 \mathrm{mg} / 100 \mathrm{~g}$-fw reported for Indian pomegranate fruits [22]. However, the level of zinc in these Tanzanian fruits compares well to the level of zinc in pineapple fruits from Tanzania [6].
This level is less than the value reported by Ishola et al. [44] for Nigerian tamarind fruits. The zinc levels found were well below the FAO and WHO permissible level of $6 \mathrm{mg} / 100 \mathrm{~g}-\mathrm{fw}$ [37].

Cadmium content was below the detection limit of the measurement, an observation similar to that reported for pineapple fruits from Dar es salaam, Tanzania and for mangoes fruits from Tanga, Tanzania by Othman [6] and Othman and Mbogo [5] respectively. The very low amount of cadmium in this fruits can probably be due to the fact that the fruits are grown in the country side well away from any industrial production, fossil fuel combustion, waste incineration or any iron and steel production which are the main sources of cadmium to the soil.

The average concentration of lead in the pomegranate fruits was $0.19 \pm 0.03 \mathrm{mg} / 100 \mathrm{~g}$-fw, a level that is much lower than the maximum permissible limit of $3 \mathrm{mg} / 100 \mathrm{~g}$-fw for lead in vegetables and thus falls within the safe limits for consumption as stated by FAO/WHO [45]. This lead level in pomegranate fruits can be attributed to the high traffic of vehicles along the Morogoro road which is near the area of sampling. High lead levels have been reported in soils close to the major roads of Dar es Salaam, Tanzania, [46] and in other countries e.g. Ethiopia [48]. However, this level of lead is generally safe and cannot lead to any health hazard for consumers.

\section{Conclusion}

The physicochemical composition of pomegranate (Punica granatum L.) fruits from Kimara, Dar es Salaam, Tanzania during open air storage-ripening were determined. Changes in proximate composition (ash, titratable acidity, crude fat, crude fibre, moisture and sugars content), ascorbic acid level, macro-nutrients and heavy metals contents during the storage ripening process were obtained. The pomegranate fruits had high moisture content $(>77.5 \%)$, low acidity $(<0.86 \% \mathrm{ca})$, low crude fat $(0.30 \mathrm{~g} / 100 \mathrm{~g}$-fw $)$, low ash content $(0.35 \mathrm{~g} / 100 \mathrm{~g}$-fw $)$, moderate crude fibre content (4.2 g/100 g-fw), high ascorbic acid content $(>20.4 \mathrm{mg} / 100 \mathrm{~g}-\mathrm{fw})$, high total sugar content $(>29.7 \%)$, moderate reducing sugar content $(25.5 \%)$ and sucrose content (5.7\%). Of the macroelements $\mathrm{K}, \mathrm{Ca}$ and $\mathrm{Na}$ determined, the highest level was of Ca i.e. $1086 \mathrm{mg} / 100 \mathrm{~g}$-fw. Heavy metals content was very low in the pomegranate fruits signifying that these fruits were free from such pollution. The compositional information of this fruit provided by this study emphasizes that pomegranate fruits can be a good source and supplement of nutrients. Comparison of our results and FAO/WHO standards reveals that this fruit from Kimara, Dar es Salaam, cannot present any health problems but can play the valuable role of fulfilling daily human diet needs as well as a health nutrient supplement.

More studies of the same properties as well as other properties on this fruit from other areas where the fruit is cultivated in Tanzania need to be undertaken as this study serves as baseline information for future studies on pomegranate fruits. 


\section{Acknowledgement}

The authors would like to acknowledge financial assistance from Quality Enhancement of College Teaching Education (QECTE) through Mkwawa University College of Education, Iringa, Tanzania. They also express their gratitude to the Chemistry Department, University of Dar es Salaam, for providing the laboratory facilities.

\section{References}

[1] Afaq, F., Saleem, M., Krueger, C.G., Reed, J.D. and Mukhtar, H (2005). Anthocyanin- and hydrolyzable tannin-rich pomegranate fruit extract modulates MAPK and NF-kappaB pathways and inhibits skin tumorigenesis in CD-1 mice. Int $\mathrm{J}$ Cancer 113(3): 423-433.

[2] Martínez, J., Melgarejo, P., Hernández, F., Salazar, D.M. and Martínez, R. (2006). Seed characterisation of $T$ five new pomegranate (Punica granatum L.) varieties. Sci. Horticulturae 110: 241-246.

[3] Mditshwa, A., Fawole, O.A., Al-Said, F., Al-Yahyai, R. and Opara, U.L. (2013). Phytochemical content, antioxidant capacity and physicochemical properties of pomegranate grown in different microclimates in South Africa. South African Journal of Plant and Soil 30: 81-90.

[4] Robert, E.P. and Stanley, L.S. (1993). Challenges in handling fresh fruits and vegetables. Academic press Inc: New York. pp 32

[5] Othman, O.C. and Mbogo, G.P. (2009). Physico-chemical characteristics of storage-ripened mango (mangifera indica 1.) fruits varieties of eastern Tanzania. Tanz. J. Sc. 35: 58-66.

[6] Othman, O.C. (2011). Physicochemical characteristic inorganic elements in off-vine ripened pineapple (Ananas comosus L.) fruits of Dar es Salaam, Tanzania. KIST. Journal of Science and Technology 1: 23-30.

[7] Othman, O.C. (2009). Physical and chemical composition of storage ripened papaya (Carica papaya L) fruits of eastern Tanzania. Tanz.J. Sci. 35: 48-56.

[8] Mbogo, G.P., Mubofu, E.B. and Othman, O.C. (2010). Postharvest changes in physical-chemical properties and levels of some inorganic elements in of vine ripened orange (Citrus sinensis) fruits $\mathrm{Cv}$ (Navel and Valencia) of Tanzania. .Afr. J. Biotechnol. 35: 58-66.

[9] Robinson, H., Maclean, K.S. and Macconnel, H.M. (1989). Heavy metal $\mathrm{pH}$, and total solid content of maple sap and syrup produced in Eastern Canada. J. Assoc. Off Anal.Chem. 72: 674-676.

[10] Divrikli, U., Saracoglu, S., Soylak, M. and Elci, L. (2003). Determination of trace heavy metal contents of green vegetables samples from Kayseri- Turkey by flame atomic absorption spectrometry. Fresenius Environ. 12: 1123-1125.

[11] Dundar, M.S. and Saglam, H.B. (2004). Determination of cadmium and vanadium in tea varieties and their infusions in comparison with 2 infusion processes. Trace Elem. Elect. 21: 60-63.

[12] Colak, H., Soylak, M. and Turkoglu, O. (2005) Determination of trace metal content of herbal and fruit teas produced and marketed from Turkey. Trace Elem. Elect. 22: 192-195.

[13] Chhatwal, G.R., Satake, M., Katyal, M., Mehra, M.C., Katyal, T. and Nagahiro, T. (1989). Encyclopidia of environmental pollution and its control.Vol.VI Environ. Anmol publications New Delhi. p. 335.

[14] Punna, R., Paruchuri, U.R. (2003). Total insoluble and soluble dietary fiber contents of Indian fruits. Journal of food composition and analysis 16: 677-685.

[15] AOAC Association of official Analytical Chemists (1990). Official methods of analysis of the Association of official analytical chemists Arlington VA. p. 1230.

[16] Inyang, U.E. and Agbo, A.U. (1995). Moisture content of mango. Trop. Sci. 35: 259.

[17] Nazarudeen, A. (2010). Nutrition composition of some lesser known fruits used by the ethnic communities and local folks of Kerala. Indian Journal of traditional knowledge 9: 398-402.

[18] Carey, D.M. and Nao, S.W. (1965). Composition of Hawaii fruits. Hawaii agricultural experimental stations: University of Hawaii. pp. 21 Al-Maiman, S.A. and Ahmad, D. (2001). J. Food Chem. 76: 437-441.

[19] Emmanuel, S.A., Taiwo, O.O. and Grace, O. (2006). Studies on the storage stabiltyof soursop (Annona muricata $L$ ) juice. Afr. J. biotechnol. 5: 1808-1812.

[20] Mitchel, H.S., Rynbergen, S., Henderika, J., Anderson, L. and Dibble, M.V. (1976). Nutrition in Heaith and Disease. J B Lippincott Company: New York.

[21] Al-Maiman, S.A. and Ahmad, D. (2001). Changes in physical and chemical properties during pomegranate (Punica granatum L.) fruit maturation. J. Food Chem. 76: 437-441.

[22] Ajay, K.M., Satarupa, M., Uday, C.B. and Pratap, C.P. (2010). Nutrient Analysis of Some Selected Wild Edible Fruits of Deciduous Forests of India: an Explorative Study towards Non Conventional Bio-Nutrition. Adv. J. F. Sci. Technol. 4: 15-21.

[23] Levine, M., Conry-Contilera, C., Wanga, Y., Welch, R.W., Washko, P.W., Dhariwa, K.R., Park, J.B., Lenarev, A. and Graundich, S. Proc. Natl. Acad Sci. 93: 3704-3709.

[24] Wall, M.M. (2006). Ascorbic acid, Vitamin A, and mineral composition of banana (Musa Sp.) and papaya (carica papaya) cultivars grown in Hawaii. Journal of food composition and Analysis. 19: 434-445.

[25] Priyanka, P., Sayed, H.M., Joshi, A.A., Jadhav, B.A. and Chilkawar, P.M. (2013). Studies on effect of different extraction methods on the quality of pomegranate juice and preparation of spiced pomegranate juice. Int. J. Food Sci. Nutr. Dietetics 2: $502-508$.

[26] Zarei, M., Azizi, M. and Bashi-Sadr. Z. (2011). Evaluation of physicochemical characteristics of pomegranate(Punica granatum L) fruits during ripening. Fruits 66: 121-129.

[27] Rathore, R.S., Kaushik, R.A.and Mathur, A.K. (2012). Studies on physico-chemical characteristics of pomegranate in Chittorgarh district of Rajasthan. Progressive Agriculture. 12: 310-317.

[28] Nagar, P.K. (1994). Effects of some ripening retardants on fruit softening of Enzymes of Kinnow mandarin fruits. Ind. J. plant physiol. 37: 122-124. 
[29] Vahid, A., Khodayar, H. and Mehdi, S, (2009). Physical and Chemical Properties of Pomegranate (Punica granatum L.) Fruit in Maturation P Stage American-Eurasian. J. Agric. \& Environ. Sci. 6: 411-416.

[30] Bolivar, F.N., Saucedo, V.C., Solis, P.S. and Sauri, D.E. (2009). Ripening of sugar apple fruits (Annona squamosa L.) developed in Yucatan, Mexico. Agrociencia 43: 133-141

[31] Asgary, S., Sahebkar, A., Afshani, M.R., Keshvari, M., Haghjooyjavanmard, S. and Rafieian-Kopaei, M. (2014). Clinical Evaluation of Blood Pressure Lowering, Endothelial Function Improving, Hypolipidemic and Anti-Inflammatory Effects of Pomegranate Juice in Hypertensive Subjects. Phytother Res. 28: 193 - 199.

[32] Basu, A. and Panugonda, K. (2009). Pomegranate juice: a heart-healthy fruit juice. Nutr Rev. 67: $49-56$.

[33] Ness, A.R. and Fowles, J.W. (1997). Frits and vegetables and cardiovascular diseases: a review. Int. J. Epidemiol. 26, 1-13.

[34] Punna, R. and Paruchuri, U.R. (2003). Total insoluble and soluble dietary fiber contents of Indian fruits. Journal of food composition and analysis 16: 677-685.

[35] Howarth, N.C., Saltzman, E. and Roberts, S.B. (2001). Dietary fiber and weight regulation. Energy density of food affects energy intake across multiple levels of fat content in lean and obese women. Am. J. Clin. Nut. 73: 1010-1018.

[36] Steffen, L.M., Jacobs, D.R., Stevens, J., Shahar, E., Carithers, T. and Folsom, A.R. (2003). Associations of whole-grain, refined grain, and fruit and vegetable consumption with risks of all-cause mortality and incident coronary artery disease and ischemic stroke: the Atherosclerosis risk in communities (ARIC) Study. Am. J. Clin. Nutr. 78: 383-390.

[37] Lairon, D., Arnault N. and Bertrais, S. (2005). Dietary fiber intake and risk factors for cardiovascular disease in French adults. .Am. J. Clin. Nutr. 82: 1185-1194.

[38] Siddhurju, P., Vijayakumari, K. and Janardhanan, K. (1996) Fibers in fruits. $J$. Food Chem. 3: 385.
[39] Soetan, K.O., Olaiya, C.O. and Oyewole, O.E. (2010). The importance of mineral elementsfor human, domestic animals and plants. A rev. Afr. J. of Food Sci. 4: 200-222.

[40] National Research Council. USA Recommended Dietary Allowances NRC (1989). Washngton, DC : National Academy press. pp 42.

[41] Mansour, E., Ben-Khaled, A., Ben-Yahya, L., Abid, M., Bachar K. and Ferchichi, A. (2014). Fiber content and quality of pomegranate (Punica granatum L.) cultivated in a Coastal Oasis. Int. J. Curr. Microbiol. App. Sci. 3: 915-924.

[42] Duruibe, J.O., Ogwuegbu, M.O.C. and Egwurugwu, J.N. (2007). Heavy metal pollution and human biotoxic effects. Int. J. Phys. Sci. 2: 112-118.

[43] Baird, C. (1995). Environmental chemistry. 2nd ed., WH Freman and Company: New York. pp. 347-391.

[44] Amarteifio, J.O. and Osas, M.O. (2006). The Chemical Composition of Selected Indigenous Fruits of Botswana. J. Appl. Sci. Environ. 10: 43 - 47.

[45] Ishola, M.M., Agbaji, E.B. and Agbaji, A.S. (1990) A Chemical Study of Tamarindus indica (Tsamiya) Fruits Grown in Nigeria. J. of the Sci. of Food and Agric. 51: 143.

[46] Commission, Codex Alimentarius (2001). Food additives and contaminants. Joint FAO/WHO Food Standards programme. pp. 1-289.

[47] Luilo, G.B. and Othman, O.C. (2006). Lead pollution in urban environments of Dar es Salaam, Tanzania. Tanz. J. Sci. 32: 61 -67 .

[48] Teju, E, Megersa, N., Chandravanshi, B.S. and Zewge, F. (2014). Lead accumulation in the roadside soils from heavy density motor way towns of eastern Ethiopia. Bull. Chem. Soc. Ethiop. 28(2): $161-176$.

[49] Dolecek, T.A., Stamler, J. and Caggiula, A.W. (1997). Methods of dietary and nutritional assessment and intervention and other methods in the Multiple Risk Factor Intervention Trial. Am. J. Clin Nutr. 65: 196S-201S 